\title{
Active vaccination with vaccinia virus $A 33$ protects mice against lethal vaccinia and ectromelia viruses but not against cowpoxvirus; elucidation of the specific adaptive immune response
}

\author{
Nir Paran ${ }^{1 * \dagger}$, Shlomo Lustig ${ }^{1 \dagger}$, Anat Zvi², Noam Erez ${ }^{1}$, Tomer Israely' ${ }^{1}$, Sharon Melamed ${ }^{1}$, Boaz Politi ${ }^{1}$, \\ David Ben-Nathan ${ }^{1}$, Paula Schneider ${ }^{1}$, Batel Lachmi ${ }^{1}$, Ofir Israeli ${ }^{2}$, Dana Stein ${ }^{2}$, Reuven Levin ${ }^{1}$ and Udy Olshevsky ${ }^{1 \dagger}$
}

\begin{abstract}
Vaccinia virus protein A33 (A33 ${ }^{\mathrm{VACV}}$ ) plays an important role in protection against orthopoxviruses, and hence is included in experimental multi-subunit smallpox vaccines. In this study we show that single-dose vaccination with recombinant Sindbis virus expressing $A 33^{V A C V}$, is sufficient to protect mice against lethal challenge with vaccinia virus WR (VACV-WR) and ectromelia virus (ECTV) but not against cowpox virus (CPXV), a closely related orthopoxvirus. Moreover, a subunit vaccine based on the cowpox virus $A 33$ ortholog (A33 ${ }^{\mathrm{CPV}}$ ) failed to protect against cowpox and only partially protected mice against VACV-WR challenge. We mapped regions of sequence variation between A33 VACV and $A 33^{C P X V}$ and analyzed the role of such variations in protection. We identified a single protective region located between residues 104-120 that harbors a putative H-2Kd T cell epitope as well as a B cell epitope - a target for the neutralizing antibody MAb-1G10 that blocks spreading of extracellular virions. Both epitopes in A33 ${ }^{\mathrm{CPXV}}$ are mutated and predicted to be non-functional. Whereas vaccination with $A 33^{\mathrm{VACV}}$ did not induce in-vivo CTL activity to the predicted epitope, inhibition of virus spread in-vitro, and protection from lethal VACV challenge pointed to the B cell epitope highlighting the critical role of residue $\mathrm{L} 118$ and of adjacent compensatory residues in protection. This epitope's critical role in protection, as well as its modifications within the orthopoxvirus genus should be taken in context with the failure of A33 to protect against CPXV as demonstrated here. These findings should be considered when developing new subunit vaccines and monoclonal antibody based therapeutics against orthopoxviruses, especially variola virus, the etiologic agent of smallpox.
\end{abstract}

Keywords: Smallpox, Subunit vaccine, A33, Cowpox, Vaccinia, Monkeypox, 1G10, Alphavirus, Sindbis, In-vivo protection

\section{Introduction}

Variola virus, the causative agent of smallpox, was eradicated following a world-wide vaccination campaign, launched by the WHO [1]. Highly conserved antigens ( $>97 \%$ sequence similarity) within the orthopoxvirus genus, allowed to achieve cross protection against variola virus by immunization with vaccinia virus (VACV) vaccine strains. In animal studies, vaccination with VACV protects mice against virulent mouse-adapted

\footnotetext{
* Correspondence: nirp@iibr.gov.l

${ }^{\dagger}$ Equal contributors

'Department of Infectious Diseases, Israel Institute for Biological Research,

P.O. box 19, Ness-Ziona 74100, Israel

Full list of author information is available at the end of the article
}

VACV (WR), ectromelia (ECTV) and cowpox (CPXV) viruses, rabbits from rabbitpox virus (RPXV) and monkeys from monkeypox virus (MPXV) [2].

Although VACV is an efficient vaccine, rare but severe side effects are associated with the vaccine. Along with the success of the eradication campaign, vaccination that was no longer required ceased. As smallpox remains a potential hazard, highly attenuated vaccine strains - e.g. MVA and LC16m8 are being extensively evaluated for potency. In addition, the approach of using protective VACV antigens is pursued by several labs, aiming at generating an efficacious and safe subunit vaccine. In this regard, A33 antigen is one of the most studied and promising candidates [3-13]. 
A33 is a type-II integral membrane glycoprotein, forming a disulfide-bonded homodimer modified with $\mathrm{N}$ - and $\mathrm{O}$ - linked glycosylations and acylation and found on the surface of extracellular virions (EV) and infected cells [14-17]. This protein was shown to form a complex with the viral proteins A36, A34 and B5, thus stabilizing their presentation on EVs $[16,18,19]$. A33 is crucial for virus egress and cell-to-cell spread, and deletion of its gene, namely A33R, results in a small plaque phenotype and virus attenuation in-vivo [20-22]. Antibodies against A33 inhibit virus spread in cell culture as assayed by inhibition of comet formation [22,23].

Using A33-based protein or DNA vaccines, several studies demonstrated the contribution of A33 to protection against VACV, ECTV and MXPV [3-13]. Moreover, antibodies to A33 have a major contribution to protection against VACV challenge [23,24].

In this work we used a recombinant Sindbis virus vector, based on the Toto 1101 attenuated strain that efficiently infect and replicate in mice without associated morbidity or mortality. This replicating virus expresses recombinant proteins cloned downstream to a potent 2nd sub-genomic promoter and therefore induces a robust immune response in mice [25]. In this work, we evaluated the efficacy of a Sindbis virus vector expressing the vaccinia virus protein $\mathrm{A} 33\left(\mathrm{~A} 33^{\mathrm{VACV}}\right)$ in protection against several orthopoxviruses. Using this system we show that A33 vaccination protected mice against VACV-WR and ECTV but failed to protect against CPXV challenge. By introducing $\mathrm{A} 33^{\mathrm{CPXV}}$ domains and residues into $\mathrm{A} 33^{\mathrm{VACV}}$, we show that protection with $\mathrm{A} 33^{\mathrm{VACV}}$ based vaccination depends on a single protective epitope in $\mathrm{A} 33^{\mathrm{VACV}}$, previously demonstrated in-vitro to serve as a target for the neutralizing antibody MAb$1 G 10$ [26,27]. We further map the role of protective residues and elaborate on the mechanism of crossprotection against orthopoxviruses.

\section{Results}

Applicability of Sindbis virus as a vaccine vector

In order to evaluate the protective capacity of $\mathrm{A} 33^{\mathrm{VACV}}$, we tested the feasibility of using an expression vector based on a replication competent, recombinant Sindbis virus (pTE3) [25]. First, we assessed the effect of vaccinating mice with this replicating vector and then we tested their susceptibility to subsequent VACV infection. To achieve these goals we vaccinated mice by intraperitoneal (i.p.) injection with two doses $(5 \mathrm{E}+8$ and $1 \mathrm{E}+9$ $\mathrm{pfu}$ ) of the parental Sindbis virus (Figure 1A). Vaccination did not cause visible signs of illness with vaccinated mice gaining weight similarly or slightly faster than unvaccinated mice (differences in AUC are not significant $\mathrm{p}>0.05$ ) (Figure $1 \mathrm{~A}$ ). No additional visible signs of illness were observed, suggesting low toxicity or reactogenicity of the vector in vaccinated mice. Next, we determined the effect of vaccination with the parental Sindbis virus on the susceptibility of the vaccinated mice to subsequent intranasal (i.n.) lethal challenge with VACV-WR of either 15 or $150 \mathrm{LD}_{50}$. All animals lost weight and succumbed to infection regardless of previous vaccination with Sindbis virus (Figure $1 \mathrm{~B}$ ). These results confirmed the applicability of this virus-based vector for the evaluation of the protective efficacy of $\mathrm{A} 33^{\mathrm{VACV}}$.

To confirm the ability of the Sindbis $\mathrm{A} 33^{\mathrm{VACV}}$ vector to express A33 in infected cells, BHK-21 cells were infected with the recombinant virus and A33 expression was determined 24 hours later by immunofluoresence microscopy. Positive staining for A33 was obtained in Sindbis-A33 infected cells (Figure 2A) as well as in the control VACV infected cells (Figure 2C) but not in cells

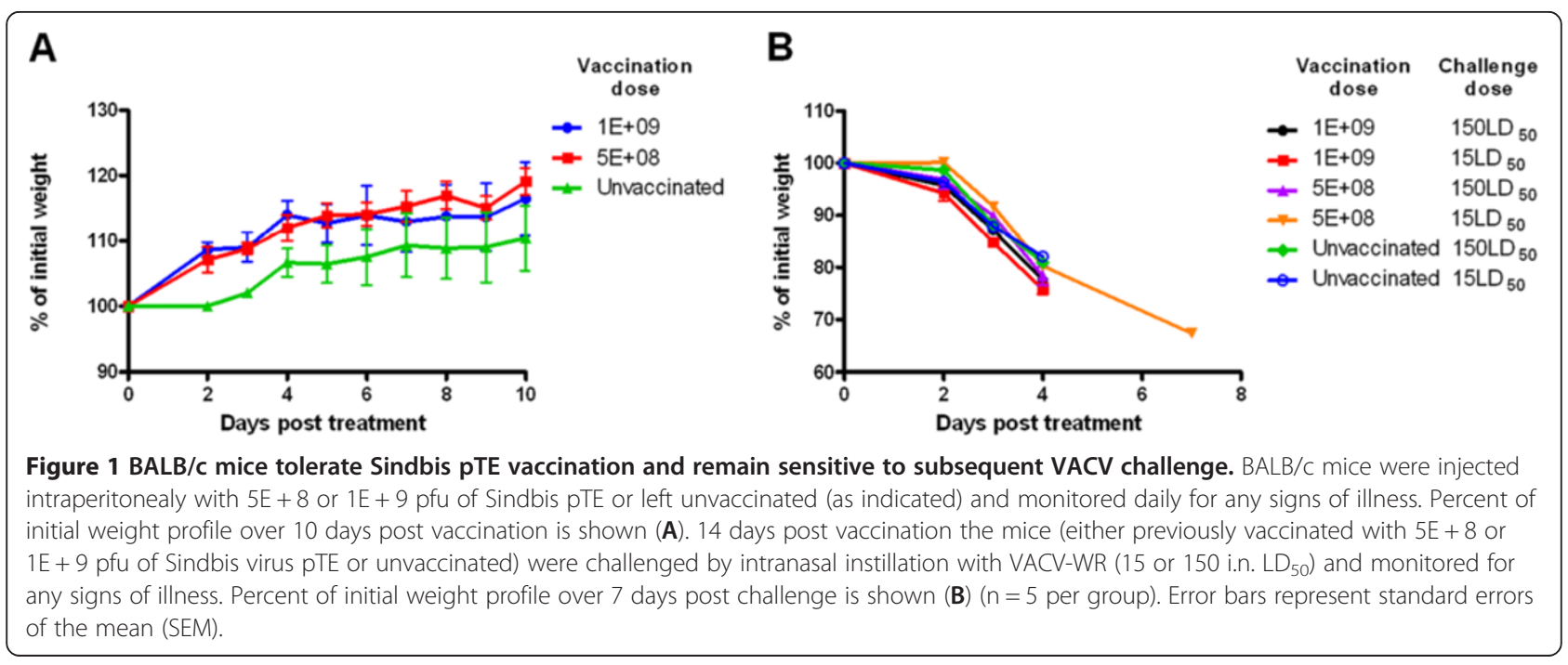




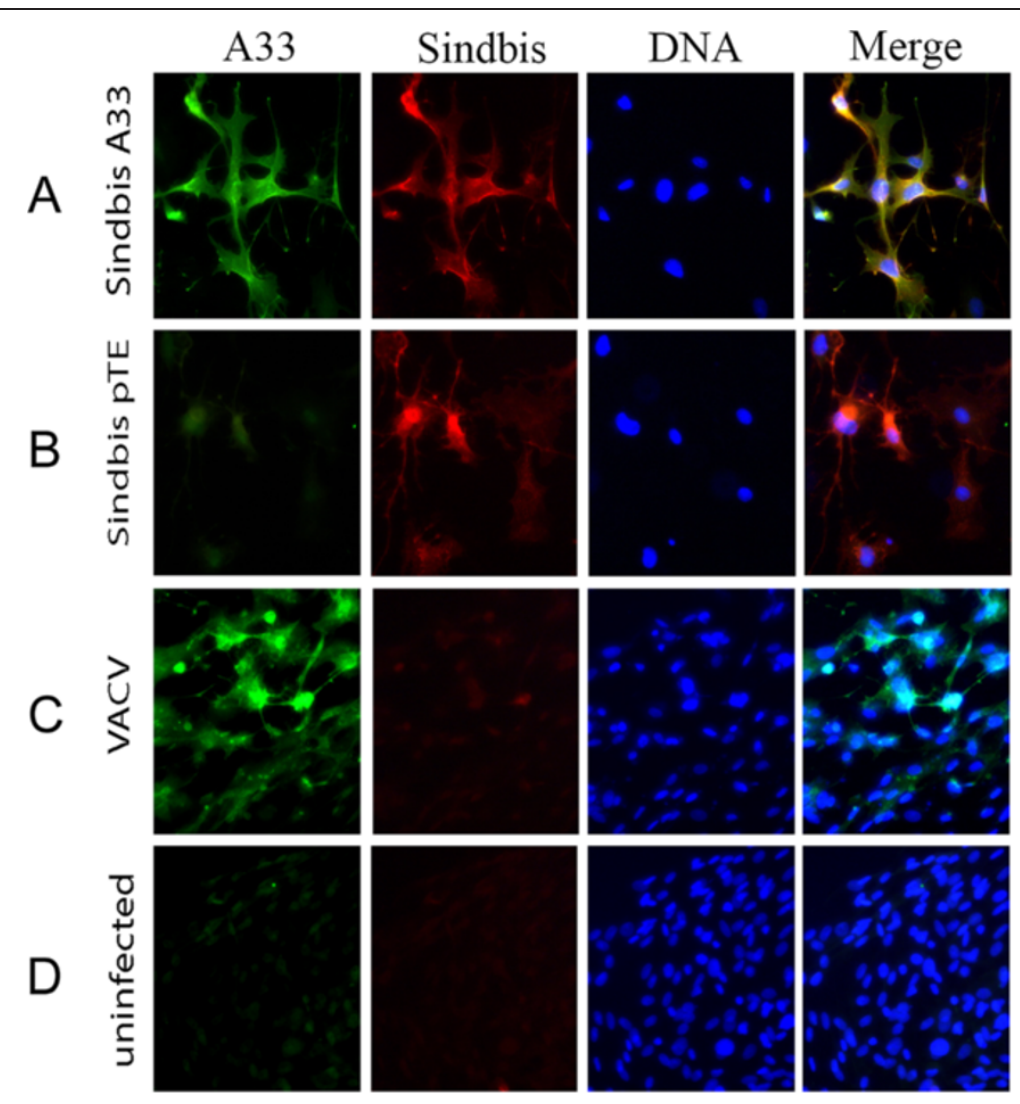

Figure 2 Expression of A33 in BHK21 cells following infection with Sindbis A33 ${ }^{\text {ACV }}$. BHK21 monolayers seeded on glass cover slides were infected at $0.1 \mathrm{MOI}$ with either Sindbis A33 $3^{\mathrm{VACV}}$ (A), Sindbis pTE (B), VACV-Lister virus (C) or left uninfected (D). 24 hours later the cells were fixed, permeabilized and stained with rabbit anti A33 and mouse anti Sindbis virus antibodies, followed by staining with goat anti rabbit antibody conjugated to a $488 \mathrm{~nm}$ fluorophore and goat anti mouse antibody conjugated to a $555 \mathrm{~nm}$ fluorophore, respectively. Cellular DNA was stained with DAPI.

infected with the control parental virus (Sindbis pTE) (Figure 2B) or in uninfected cells (Figure 2D), where only faint non-specific staining was observed. Staining for Sindbis virus in cells infected with Sindbis confirmed the infection efficiency in both samples (Figure 2A and B).

\section{Sindbis A33 protects against VACV-WR and ECTV \\ challenge}

To evaluate the protective efficacy of Sindbis $A 33^{\mathrm{VACV}}$, $\mathrm{BALB} / \mathrm{c}$ mice were vaccinated by single i.p. injection with $10^{7} \mathrm{pfu}$ of Sindbis A33 $3^{\mathrm{VACV}}$ or Sindbis pTE as a negative control. Fifteen days post vaccination animals were challenged with orthopoxviruses.

When VACV-WR, the commonly used mouse adapted strain was used to challenge the mice by intranasal (i.n.) instillation (lethal dose of $4 \times 10^{6} \mathrm{pfu}$ corresponding to $200 \mathrm{LD}_{50}$ ), all A33 ${ }^{\mathrm{VACV}}$ vaccinated mice survived while control Sindbis pTE vaccinated mice and unvaccinated animals succumbed to infection (Figure 3A). Although Sindbis $\mathrm{A} 33^{\mathrm{VACV}}$ vaccination prevented mortality, it did not prevent morbidity (Figure $3 \mathrm{~B}$ ). A $33^{\mathrm{VACV}}$ vaccinated mice lost weight similarly to pTE control vaccinated mice. Yet, at day 8 post challenge, $\mathrm{A} 33^{\mathrm{VACV}}$ vaccinated mice began to recover while all control animals died (Figure 3B).

Intravenous infection with VACV-WR leads to a disease visually manifested by pock formation on the tails of the infected mice that can be prevented by vaccination with VACV, as we have shown previously [28]. We used this model to evaluate the protective efficacy of Sindbis $\mathrm{A} 33^{\mathrm{VACV}}$. We vaccinated CD-1 mice with $10^{7} \mathrm{pfu}$ Sindbis $\mathrm{A} 33^{\mathrm{VACV}}$ and 14 days later we challenged these animals with $10^{4} \mathrm{pfu}$ VACV-WR by i.v. injection. Control pTE and unvaccinated animals exhibited multiple pocks on their tails (Figure $3 \mathrm{C}$ ). In contrast, Sindbis $\mathrm{A} 33^{\mathrm{VACV}}$ vaccination significantly reduced pock formation by $70 \%(\mathrm{P}<0.001)$. Intradermal scarification with the conventional smallpox vaccine VACV-Lister completely prevented pock formation. Thus, our data demonstrate that single vaccination with Sindbis A $33^{\text {VACV }}$ prevents death and reduces the number of dermal pocks caused by VACV-WR infection.

We then challenged the Sindbis virus based vaccine with ECTV - the causative agent of mousepox which is 


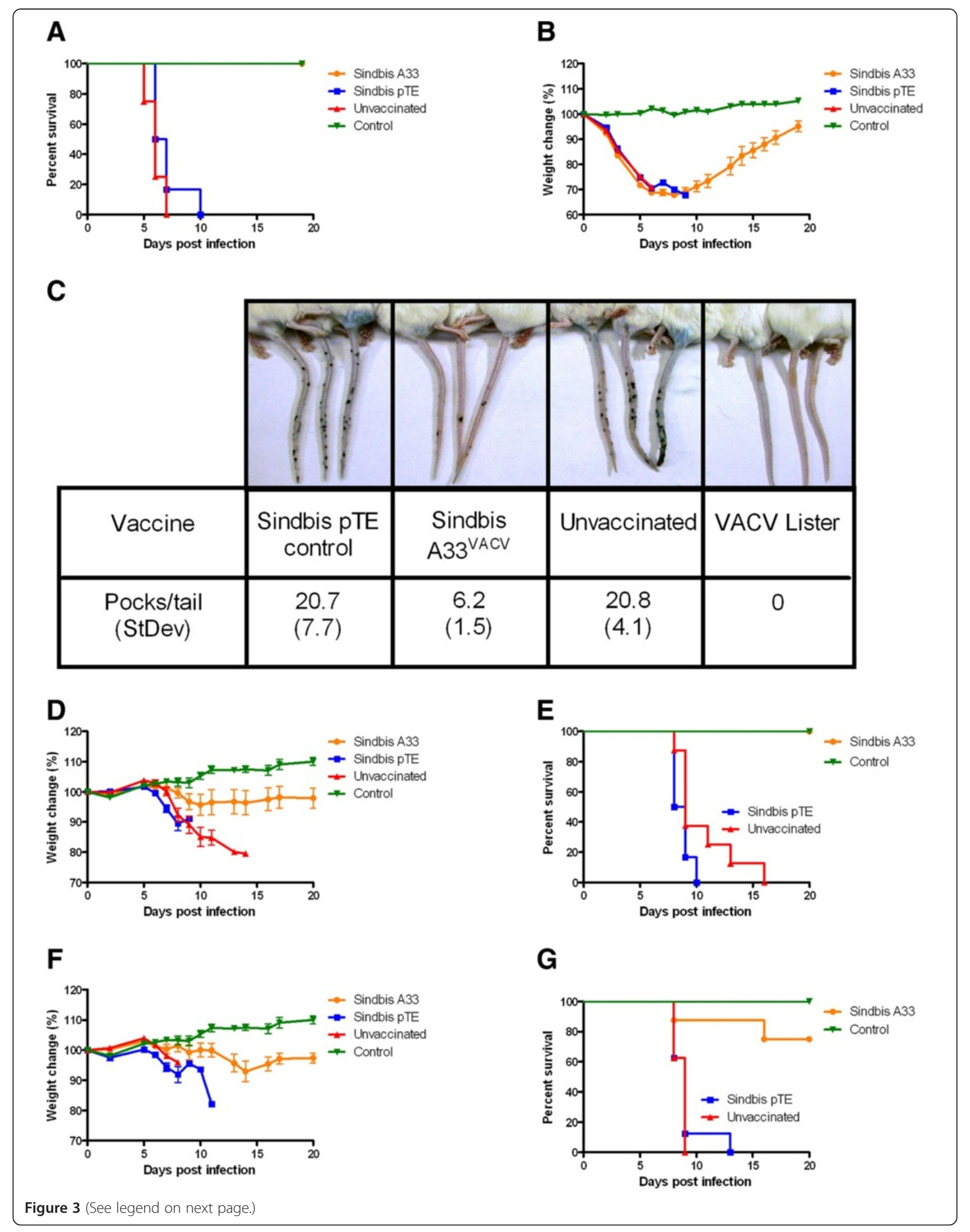


(See figure on previous page.)

Figure 3 Protection against orthopoxvirus exposure by Sindbis $A 33^{\mathrm{VACV}}$. BALB/c mice were vaccinated intraperitonealy with $1 \mathrm{E}+7 \mathrm{pfu}$ of the indicated viruses: Sindbis A33 ${ }^{\mathrm{VACV}}$, Sindbis PTE or left unvaccinated. Where indicated (Figure 3C), mice were vaccinated by tail scarification with $1 \times 10^{6}$ VACV-Lister. Two weeks later, the mice were challenged with VACVWR (4E +6 pfu i.n. corresponding to 200LD $D_{50}$ ) and monitored for mortality (A) and weight loss as a measure of morbidity (B). Pocks on the tails were induced in vaccinated or unvaccinated CD-1 mice 14 days post vaccination by intravenous injection with $1 \mathrm{E}+04$ pfu of VACV-WR (C). Pocks on the tails were stained with Trypan blue and counted. Vaccinated mice were challenged with ECTV (10 pfu i.n. corresponding to 10LD ${ }_{50}$ ) (D, E) or ECTV by i.f.p. injection (30 pfu corresponding to 3 $\left.L_{50}\right)(\mathbf{F}, \mathbf{G})$. Mice were weighed daily to monitor morbidity and checked for mortality ( $n=6$ per group for Figures 3 A \& $B, n=5$ per group for Figure $5 C$ and $n=7$ per group for Figures 3D, E, F \& G). Error bars represent standard errors of the mean (SEM).

considered the best small animal model for human smallpox $[29,30]$. BALB/c mice are highly susceptible to ECTV infection either by i.n. instillation or by intrafootpad (i.f.p) injection. We determined the $\mathrm{LD}_{50}$ values for $\mathrm{BALB} / \mathrm{c}$ as: i.n. $\mathrm{LD}_{50}=1 \mathrm{pfu}$ and i.f.p $\mathrm{LD}_{50}=10 \mathrm{pfu}$ ([29] and our unpublished data).

We vaccinated $\mathrm{BALB} / \mathrm{c}$ mice with Sindbis $\mathrm{A} 33^{\mathrm{VACV}}$ and 14 days later challenged them with $10 \mathrm{i} . \mathrm{n}-\mathrm{LD}_{50}$ or 3 i.f.p-LD ${ }_{50}$ ECTV (Figure 3D, E and Figure 3F, G, respectively). Following i.n. challenge, control unvaccinated mice or pTE vaccinated animals started to lose weight after 6 days, gradually deteriorated and succumbed to infection within two weeks (mean time to death (MTTD) of 10.5 and 8.7 , respectively). In contrast, vaccination with Sindbis $\mathrm{A} 33^{\mathrm{VACV}}$ prevented mortality and significantly reduced the extent of weight loss $(\mathrm{p}<0.01$ comparing the area under the curve of A33 vaccinated vs pTE or unvaccinated mice, Figure 3D).

$\mathrm{A} 33^{\mathrm{VACV}}$ also protected against 3 i.f.pLD $\mathrm{pD}_{50}$ challenge conferring $80 \%$ protection from lethality and reducing the extent of weight loss (Figure 3F, G). In contrast, control Sindbis pTE vaccinated mice or unvaccinated mice deteriorated faster and did not survive the challenge.

\section{CPXV escapes A33 $3^{\text {VACV }}$ induced immunity}

CPXV is a rodent orthopoxvirus found in nature in the northern parts of Europe and Asia and occasionally causes emerging zoonosis [2,31,32]. This virus causes a lethal disease in lab mice that can be prevented by smallpox vaccination [28].

To measure the potency of $\mathrm{A} 33^{\mathrm{VACV}}$ based vaccine against CPXV infection we vaccinated BALB/c mice with Sindbis $\mathrm{A} 33^{\mathrm{VACV}}$ and 14 days later challenged them with a lethal dose of CPXV ( 3 i.n. $L_{50}$ ). In contrast to the efficient protection against VACV-WR and ECTV, A33 $3^{\mathrm{VACV}}$ vaccinated mice were not protected from a lethal challenge with CPXV (Figure 4A, B). All mice lost weight and died at a similar rate regardless of vaccination. To check whether the basis for the failure of $\mathrm{A} 33^{\mathrm{VACV}}$ to protect against CPXV is sequence variation in A33, we generated a recombinant Sindbis virus encoding the CPXV ortholog of A33 (A33 $\left.{ }^{\mathrm{CPXV}}\right)$. Similar to vaccination with A33 ${ }^{\mathrm{VACV}}$, vaccination with $\mathrm{A} 33^{\mathrm{CPXV}}$ neither protected nor prevented morbidity against 3 i.n. $L_{50}$ challenge of CPXV
(Figure 4C, D), excluding the possibility that sequence variation prevents $\mathrm{A} 33^{\mathrm{VACV}}$ from protecting against $\mathrm{CPXV}$ challenge. When we tested the ability of $\mathrm{A} 33^{\mathrm{CPXV}}$ to protect against VACV-WR challenge (20 i.n. $\left.\mathrm{LD}_{50}\right)$, A33 ${ }^{\mathrm{CPXV}}$ vaccinated mice were morbid and $40 \%$ succumbed to infection whereas all $\mathrm{A} 33^{\mathrm{VACV}}$ survived and were less morbid (Figure 4E, F). All control Sindbis pTE vaccinated and unvaccinated mice succumbed to the infection. Thus, the data indicate that CPXV evades the protective immune response induced by $\mathrm{A} 33^{\mathrm{VACV}}$ or by $\mathrm{A} 33^{\mathrm{CPXV}}$. We further show that unlike $\mathrm{A} 33^{\mathrm{VACV}}$, $\mathrm{A} 33^{\mathrm{CPXV}}$ only partially protects against VACV-WR challenge, suggesting that protective epitope(s) in $\mathrm{A} 33^{\mathrm{VACV}}$ that confer protection against VACV and ECTV are modified in $\mathrm{A} 33^{\mathrm{CPXV}}$ making $\mathrm{A} 33^{\mathrm{CPXV}}$ less protective.

\section{Mapping the protective region in A33}

To elucidate the mechanism underlying the inability of A33 to protect against CPXV, we looked for differences in $\mathrm{A} 33$ between $\mathrm{A} 33^{\mathrm{VACV}}$ and $\mathrm{A} 33^{\mathrm{CPXV}}$. Additional sequences of monkeypox Zair (MPXV-ZAR), ectromelia virus Moscow (ECTV-Moscow) and Variola major virus starin Bangladesh (VARV-BGD74_sol) were included to elaborate on the role of these sequence variations in pathology of virulent orthopox and protection capacity of molecular vaccines. Comparison of the amino acid (aa) sequences of VACV and CPXV revealed two main regions harboring differences between VACV and CPXV encompassing aa S82-S89 and L112-L118 which we termed CP-I and CP-II, respectively (Figure 5A). The aa changes in CP-I region are unique to CPXV while changes in CP-II appear also in the listed species. The aa sequence of A33 is identical for VACV-WR (the challenge strain) and for VACV-Lister (the vaccine strain). In order to elaborate on the role of these two regions in protection, two chimeric molecules were constructed by replacing the $\mathrm{A} 33^{\mathrm{VACV}} \mathrm{CP}-\mathrm{I}$ and $\mathrm{CP}-\mathrm{II}$ regions with the corresponding CPXV sequences. The chimeric A33 genes were introduced to the Sindbis expression system. Mice were vaccinated with the recombinant Sindbis virus encoding $\mathrm{A} 33^{\mathrm{VACV}}, \mathrm{A} 33^{\mathrm{CPXV}}$ or the chimeric $\mathrm{A} 33$ proteins, and 14 days post vaccination were challenged by intranasal instillation with either VACV-WR $\left(20 \mathrm{LD}_{50}\right)$ or CPXV $\left(3 \mathrm{LD}_{50}\right)$. Replacement of the $\mathrm{A} 33^{\mathrm{VACV}}$ backbone 


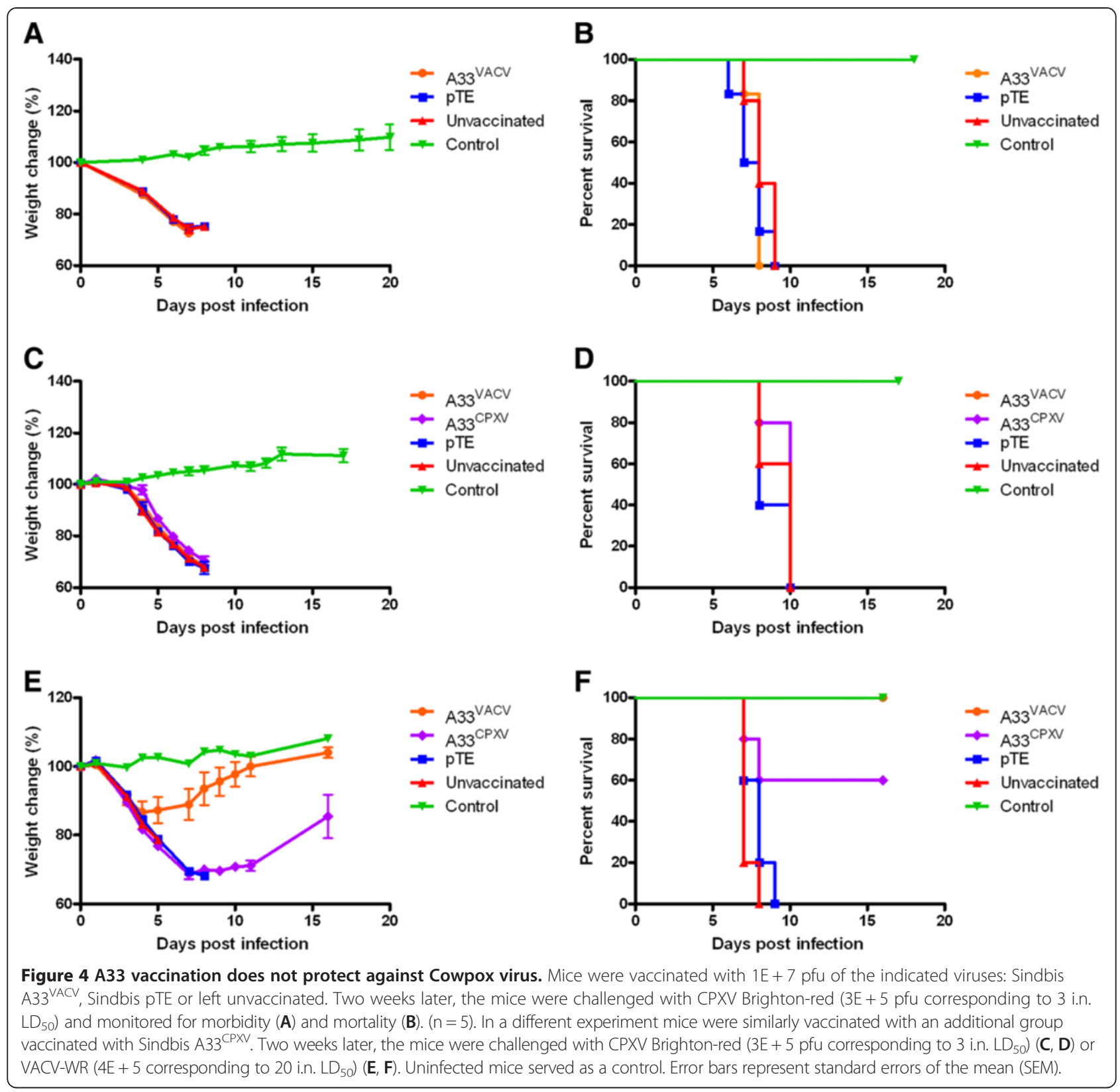

with A33 CP-I region did not affect the inherent protective capacity of $\mathrm{A} 33^{\mathrm{VACV}}$ and the mice recovered similarly to $\mathrm{A} 33^{\mathrm{VACV}}$ vaccination (Figure $5 \mathrm{~B}$ ). However, replacement of the $\mathrm{A} 33^{\mathrm{VACV}}$ backbone with $\mathrm{A} 33 \mathrm{CP}-\mathrm{II}$ region resulted in loss of protection against VACV-WR challenge (Figure 5B). None of the tested constructs provided protection against CPXV challenge (Figure $5 \mathrm{C}$ ). The loss of protection that resulted from replacement of the CP-II region of VACV with the corresponding CPXV region, suggests that CP-II harbors protective epitope(s). This epitope is not protective in the corresponding CP-II region of CPXV.
Identification of the critical residues for protection in A33 Next, we wanted to identify which of the residues in $\mathrm{CP}$ II contribute to protection. The CP-II region in $\mathrm{A} 33^{\mathrm{CPXV}}$ harbors the following amino acid substitutions compared to A33 ${ }^{\mathrm{VACV}}$ : L112F, Q117K and L118S (Figure 6A). The L112F substitution is shared also by variola virus (VARV-BGD74_sol) while the Q117K and L118S substitutions are found in monkeypox (MPXV-ZAR) and ectromelia (ECTV-Moscow) but not in VARV. Both MPXV and ECTV share also the S120E substitution. To check which of these substitutions abrogates protection, we generated modified $\mathrm{A} 33^{\mathrm{VACV}}$ genes harboring the 


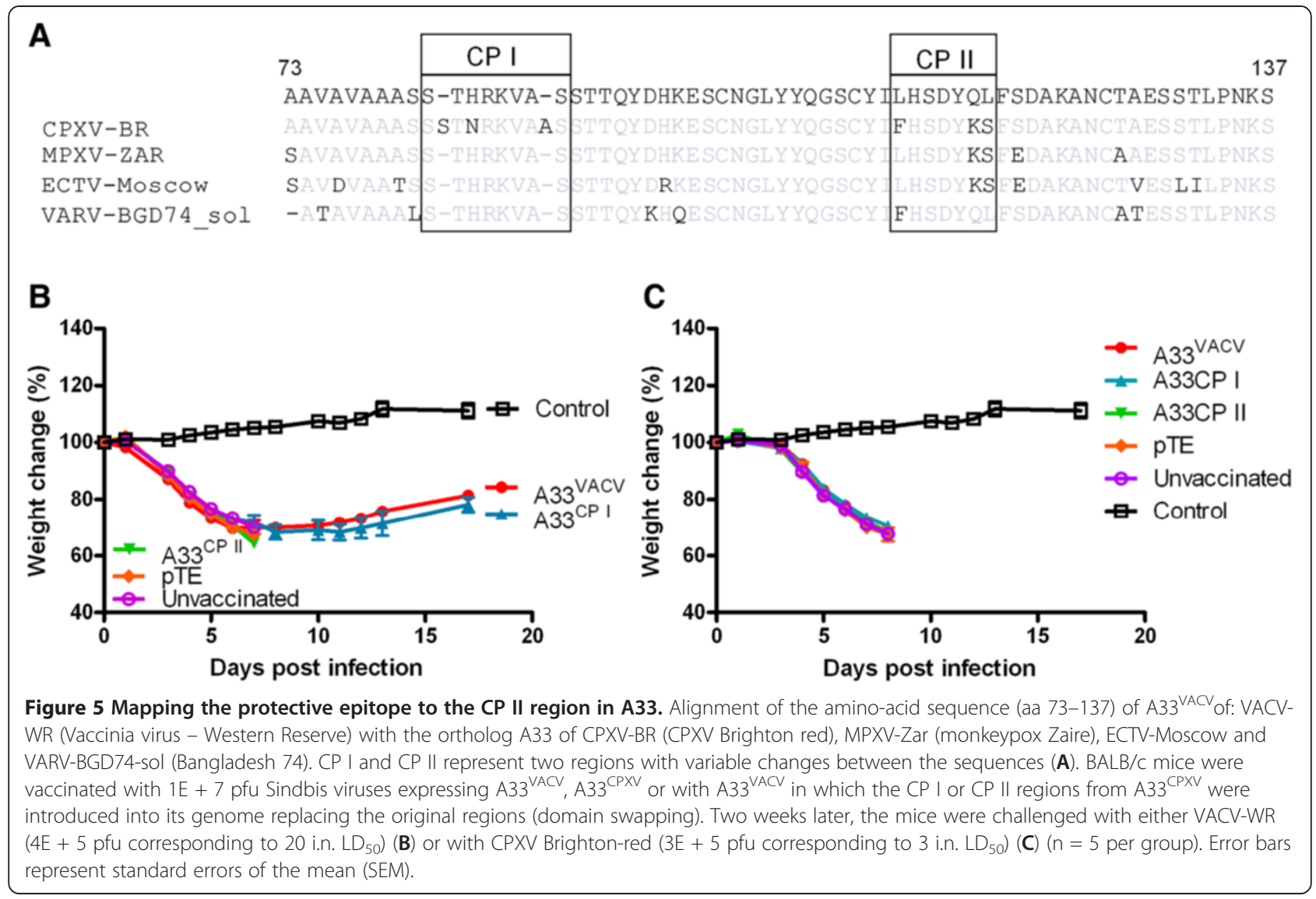

L112F, Q117K and L118S substitutions on the backbone of $\mathrm{A} 33^{\mathrm{VACV}}$. In addition, we also generated a double mutant A33 gene (Q117K-L118S). These modified A33 ${ }^{\mathrm{VACV}}$ genes were cloned into the Sindbis expression system. Recombinant Sindbis viruses were produced and expression of the modified A33 genes was confirmed by infection of BHK 21 cells followed by Western blot analysis of the cell lysates (Figure 6B). A33 is post-translationally modified in cells ( $\mathrm{N}^{\prime}$ and $\mathrm{O}^{\prime}$ glycosylations and acylation) resulting in a well-known multiple band pattern in SDSPAGE $[14,16,19]$. All Sindbis viruses expressed the modified $\mathrm{A} 33^{\mathrm{VACV}}$ genes, yet certain differences in the multiple band pattern could be observed, mainly in the double mutant A33 (Q117K-L118S). Expression of the E1 and E2 sindbis virus proteins and $\beta$-Tubulin confirm the specificity of A33 detection and serve as infection and loading controls.

Next, we evaluated the effect of the aa substitutions on the capacity of A33 to induce immune response and protection. To analyze the effect of the aa substitutions on ability of A33 to mount cytotoxic CD8+ T cell lymphocyte (CTL) dependent cytotoxicity, we performed in-silico analysis of A33 potential CTL epitopes utilizing 3 independent experimentally based algorithms: NetMHC, SYFPEITHI and BIMAS [33-35]. Since evaluation of the protective ability of $\mathrm{A} 33$ is performed in BALB/c mice, the analysis was set to predict epitopes that can bind the BALB/c MHC class I molecule ( $\mathrm{H}-2 \mathrm{Kd}$ and $\mathrm{H}-2 \mathrm{Dd}$ alleles). All three algorithms identified a single $\mathrm{H}-2 \mathrm{kd}$ prevalent 9-mer potential CTL epitope in the entire $\mathrm{A} 33^{\mathrm{VACV}}$ gene spanning aa Y104 to L112, in which the essential anchoring residue L112 is located at the CP-II region. In addition, all three algorithms predicted that the 9-mer peptide harboring the L112F substitution, representing the CPXV orthologous peptide, would lose the ability to bind the MHC molecule, a prerequisite to elicit CD8+ T-cell cytotoxicity.

To check whether the 9-mer epitope in CPII harboring L112 is a functional CTL epitope, and whether the L112F substitution abrogates it, BALB/c mice were vaccinated with sindbis $\mathrm{A} 33^{\mathrm{VACV}}$ and 14 days later were tested for their ability to mount in-vivo CTL activity (Table 1). Vaccination with VACV-Lister, the licensed smallpox vaccine and the $\mathrm{H}-2 \mathrm{Kd}$ immune dominant $\mathrm{T}$-cell epitope of VACV A52 [36] were used as positive controls. Naïve mice and the unrelated influenza virus $\mathrm{H}-2 \mathrm{Kd}$ CTL epitope (Influenza A/H3N2/Texas/1/77 NP 147-158) [37] were used to calculate specific lysis. In support of previous reports [36], VACV-Lister vaccinated mice mounted about $40 \%$ specific lysis of A52 labeled cells unlike naïve, 


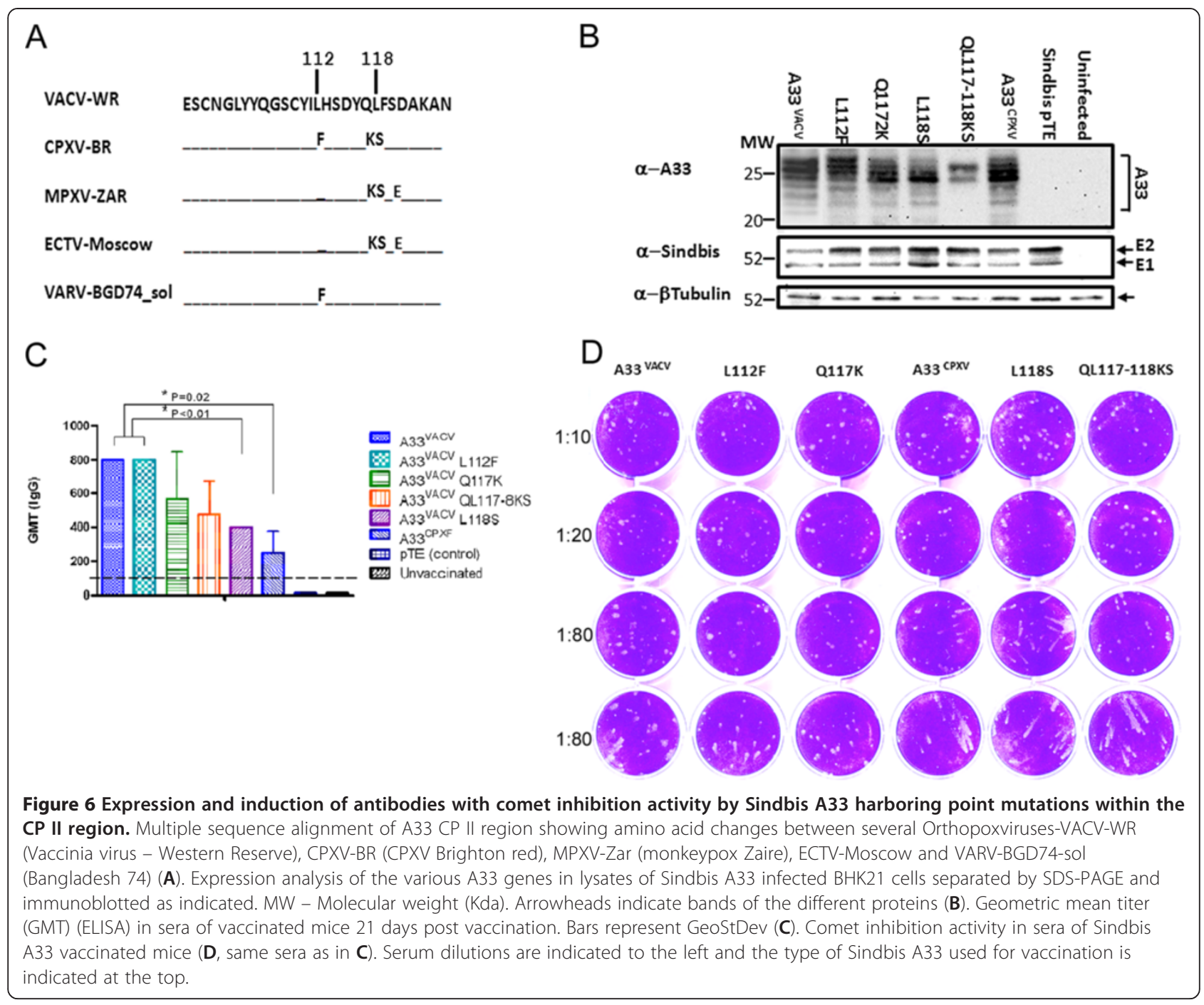

unvaccinated mice. The predicted 9-mer $\mathrm{H}-2 \mathrm{Kd}$ CTL epitope spanning aa Y104 to L112 of A33 ${ }^{\mathrm{VACV}}$ did not mount significant specific lysis neither following sindbis A33 $\mathrm{VACV}$ vaccination nor following VACV-Lister vaccination. Interestingly, peptide harboring L112F substitution, predicted to prevent CTL activity, mounted a weak, yet significant response. In summary, our results do not support the presence of a functional $\mathrm{H}-2 \mathrm{Kd}$ CTL epitope spanning

Table 1 In vivo CTL activity to A33 peptides in vaccinated mice

\begin{tabular}{ccc}
\hline Vaccination & Specific peptide & \% Specific lysis (StDev) \\
\hline Sindbis A33 & & $0(1.3)$ \\
VACV Lister & A33 & $2.5(2.9)$ \\
Sindbis A33 & & \\
VACV & A33 $33^{\text {CPXV }}(104-112)$ & $6.1(2.8)$ \\
VACV Lister & A52 & $40.4(6.3)$ \\
\hline
\end{tabular}

In vivo CTL activity to the indicated peptides (middle column) was measured 14 days following vaccination of BALB/c mice with the indicated viruses (left column). Specific lysis (\% and StDev) is depicted in the right column.
aaY104 to L112. Therefore, the data does not support the hypothesis that immune evasion of A33 by CPXV is due to the loss of a CTL epitope through the L112F substitution.

We then tested the level of serum IgG antibodies against A33 following vaccination with the various A33 derivatives. All A33 derivatives induced specific antibodies as determined by ELISA using $\mathrm{A} 33^{\mathrm{VACV}}$ as the capture antigen (Figure 6C). Yet, lower antibody titers were detected following vaccination with $\mathrm{A} 33^{\mathrm{CPXV}}$ or the L118S substitution $(\mathrm{P}=0.02$ and $\mathrm{P}<0.01$ compared to $\mathrm{A} 33^{\mathrm{VACV}} / \mathrm{A} 33^{\mathrm{VACV}} \mathrm{L} 112 \mathrm{~F}$, respectively). As protective antibodies against A33 were previously demonstrated to inhibit EV spread in culture, we analyzed the capacity of the different sera to inhibit EV spread assayed by comet formation inhibition. A33 ${ }^{\mathrm{VACV}}$ as well as the L112F or Q117K mutants inhibited comet formation. In contrast, sera from $\mathrm{A} 33^{\mathrm{CPXV}}$ or $\mathrm{L} 118 \mathrm{~S}$ vaccinated mice poorly inhibited comet formation (Figure 6D). Comet inhibition 
by serum from the double substitution Q117K - L118S vaccinated mice inhibited EV spread only partially.

To elucidate the protective capacity of these variations, vaccinated mice were challenged by intranasal instillation with VACV-WR (20 $\mathrm{LD}_{50}$, Figure 7). Whereas L112F and Q117K substitutions protected mice similarly to $\mathrm{A} 33^{\mathrm{VACV}}$ (100\% survival), L118S substitution resulted in complete loss of protection (Figure 7A). The Q117K L118S double substitution resulted in partial protection ( $40 \%$ survival), and the recovery rate of the surviving animals in this group was slower in comparison to $\mathrm{A} 33^{\mathrm{VACV}}$ vaccinated mice $(\mathrm{p}<0.004)$ (Figure $\left.7 \mathrm{~B}\right)$. Thus, our data indicates that of the several amino acid differences between the $\mathrm{A} 33^{\mathrm{VACV}}$ and $\mathrm{A} 33^{\mathrm{CPXV}}$, L118 as part of a major protective epitope, significantly contributes to the protection afforded by active vaccination with A33, most likely through induction of protective humoral immunity.

\section{Discussion}

In the present study we evaluated the applicability of a Sindbis-virus based vector for the evaluation of the protective efficacy of $\mathrm{A} 33^{\mathrm{VACV}}$. Previous reports demonstrated the protective capacity of A33 against different orthopoxviruses such as VACV-WR, ECTV and MPXV $[3-8,13]$. We show that a single-dose vaccination of Sindbis $\mathrm{A} 33^{\mathrm{VACV}}$ efficiently protected mice against virulent VACV-WR and ECTV challenge, but failed to protect against CPXV challenge. Furthermore, homologous vaccination with $\mathrm{A} 33^{\mathrm{CPXV}}$ failed to protect against $\mathrm{CPXV}$ and only partially protected against VACV-WR. We identified a single protective region in $\mathrm{A} 33^{\mathrm{VACV}}$ located between residues 104-120 that harbors a putative $\mathrm{H}$ 2Kd CD8+ T cell epitope and a B cell epitope. This B cell epitope was shown to be a target for the neutralizing antibody MAb-1G10 that blocks spreading of extracellular virions $[26,27]$. Both epitopes are affected in $\mathrm{A} 33^{\mathrm{CPXV}}$ by 3 amino acids (aa) substitutions L112F, Q117K and L118S and shown to be non-functional. Vaccination with a $\mathrm{A} 33^{\mathrm{VACV}}$, modified to contain each of these substitutions, revealed the critical role of L118 in protection against VACV-WR and in blocking of EV spread by antibodies. These results support previous studies which mapped the critical role of L118 in binding the monoclonal neutralizing antibody MAb-1G10 and the consequence of each of these substitutions on binding of this antibody [26,27]. Since A33 is considered an important contributor to future smallpox subunit vaccines which might also be used against other orthopoxvirus infections such as MPXV, and antibodies to A33 are developed for treatment of orthopoxvirus infections, unraveling the basis for this protective ability at the single aa level is of major importance.

In-silico analysis of A33 identified a potential CTL epitope in which L112 is a pivotal anchoring residue. L112F substitution representing the CPXV orthologous peptide, abolished the predicted binding to the $\mathrm{H}-2 \mathrm{Kd}$ molecule thus impairing the ability of A33 to elicit a cellular immune response. The very same substitution is also found in the VARV homologue A33 ${ }^{\mathrm{VARV}}$ (Figure 6A) making this specific residue of interest. In contrast to the insilico predictions, A33 vaccination did not induce CTL activity to the 9 mer Y104 to L112 predicted epitope of A $33^{\text {VACV }}$ (Table 1). Surprisingly the L112F substituted epitope (found in $\mathrm{A} 33^{\mathrm{CPXV}}$ ) induced a low level of $\mathrm{CTL}$ activity, yet it did not correlate with in-vivo protection. Since L112F substitution retained the protective ability of A33 we conclude that at least in the BALB/c mouse model, this epitope does not induce T-cell dependent cytotoxicity. As L112F substitution is also found in $\mathrm{A} 33^{\mathrm{VARV}}$, we tested the possibility that this substitution may render VARV resistant to A33-based vaccination. In humans, two overlapping predicted $\mathrm{A} 33^{\mathrm{VACV}}$ CTL epitopes were mapped at this region spanning aa 102-111
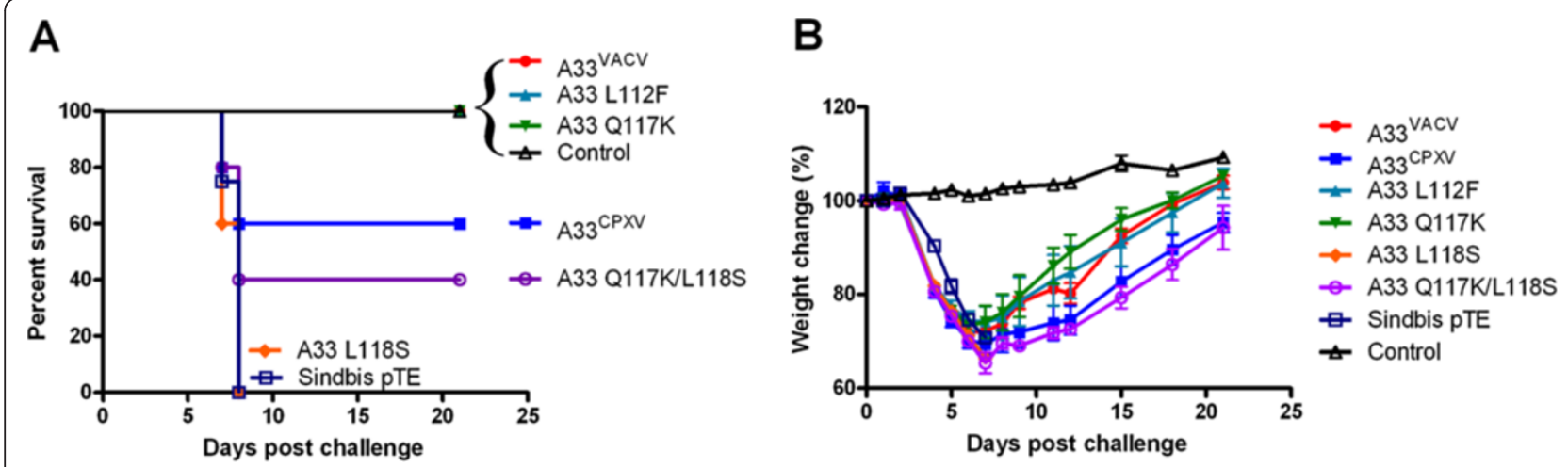

Figure 7 Mapping the protective epitope in A33. Mortality (A) and morbidity (B) in mice vaccinated with various A33 constructs. BALB/C mice were vaccinated with $1 E+7$ pfu of Sindbis viruses expressing the various A33 proteins or with a control Sindbis pTE as indicated. 14 days later the mice were challenged by i.n. instillation with VACV-WR (4E +5 pfu corresponding to 20 LD 50 ). ( $n=5$ per group). Error bars represent standard errors of the mean (SEM). 
(based on the A0201 allele of the HLA-A2 supertype) [38] and 109-118 (NetCTL prediction, CBS). Despite strong in-vitro binding of the former epitope (aa 102111) to A0201 allele, CTL activity (IFNY release) was not detected [39]. Additionally, the L112F variation found in $\mathrm{A} 33^{\mathrm{VARV}}$ is not predicted to affect the anchoring to the A0201 molecule. Thus, our experimental data and previous studies do not support the presence of a functional CTL epitope within the CP-II region, suggesting that F112 substitution found in A33 VARV most probably will not abrogate protective immunity through vaccination with $\mathrm{A} 33^{\mathrm{VACV}}$.

We evaluated several single aa substitutions in the CPII region and demonstrated that L118 is the only residue which is crucial for protection against VACV-WR. These results are in complete agreement with the mapping of the binding epitope of the protective/neutralizing monoclonal antibody MAb-1G10 [26]. In that study, the L118S change in MPXV was shown to be detrimental for the MAb-1G10 binding and the Q117K substitution partially restored this binding [26]. In our hands, sera from mice vaccinated with an A33 harboring the L118S substitution exhibited a lower antibody titer reflected by reduced comet inhibition potency. It was previously demonstrated that comet inhibition activity correlates with protection against lethal VACV-WR challenge [40]. It appears that the inability of A33 to protect BALB/c mice against CPXV challenge, most likely results from the inability of the $\mathrm{A} 33^{\mathrm{VACV}}$-induced protective antibodies to recognize $\mathrm{A} 33^{\mathrm{CPXV}}$. It is possible that the $\mathrm{L} 118 \mathrm{~S}$ substitution, replacing a non-polar hydrophobic with a polarhydrophilic residue, interferes with antibody binding to the epitope containing L118.

We showed that vaccination with $\mathrm{A} 33^{\mathrm{CPXV}}$ did not protect against CPXV challenge and only partially protected against VACV-WR challenge (Figure 4). These results support the study mentioned above, using the MPXV ortholog of $\mathrm{A} 33\left(\mathrm{~A} 33^{\mathrm{MPXV}}\right)$ which also partially protected against VACV-WR challenge [26]. Unlike CPXV, both MPXV and ECTV encode the E120 residue that is believed to compensate for the L118S substitution found in $\mathrm{A} 33^{\mathrm{MPXV}}$ and $\mathrm{A} 33^{\mathrm{ECTV}}$ (Figure 6A). In this work we further show the critical role of L118 in protection against lethal challenge with VACV-WR by active vaccination. Having the same mouse model for VACV-WR, CPXV and ECTV, allowed us to evaluate the differential crossprotection capacity of $\mathrm{A} 33$, and allowed to demonstrate the critical role of L118 and the compensatory role of Q117 and E120.

The results also agree with previous work by $\mathrm{He}$ et al. [27], substantiating the essential role of L118 in binding of protective antibodies to A33. In that work, an important role in antibody binding to the epitope is attributed to the D115 residue, yet D115 is conserved between
VACV and CPXV excluding its contribution to the mechanism utilized by CPXV to evade A33 immunity. Our work shows that active vaccination with A33 induces immunity to a single protective epitope and suggests that the mechanism of protection involves induction of MAb-1G10 like neutralizing antibodies. This epitope overlaps an immunogenic region in A33, previously mapped in primates to mount antibody response $[5,24,41]$, further emphasizing the importance of this region for future vaccines.

We show that the L118S substitution abrogated protection, which was partially restored, by the double mutant Q117K-L118S. This correlates with partial restoration of the binding of MAb-1G10 antibodies to A33 by the Q117K substitution [26]. This suggests that beside the major L118 residue, other residues, within the protective epitope, contribute to protection. Indeed, $\mathrm{A} 33^{\mathrm{VACV}}$ protects BALB/c against ECTV challenge. $\mathrm{A} 33^{\mathrm{ECTV}}$ bares the same Q117K-L118S substitutions, and similarly to MPXV has an additional S120E substitution, not found in CPXV. This substitution was shown to improve binding of the MAb-1G10 neutralizing antibody [26], pointing toward E120 as a compensatory residue. It is possible that boosting immunization with A33 enhances an immune response through additional weak epitopes that support protection in very low challenge doses of CPXV [42].

Having demonstrated that replacement of CP-II eliminates the protection afforded by A33 and that CP-I replacement was as protective as $\mathrm{A} 33^{\mathrm{VACV}}$ it was reasonable to suggest that a major protective epitope is located within CP-II, as demonstrated in the manuscript. Whether CP-I replacement synergize with CP-II cannot be simply tested because CP-II of CPXV was already associated with $100 \%$ lethality. Nevertheless, based on the partial protection against VACV-WR afforded by vaccination with $\mathrm{A} 33^{\mathrm{CPXV}}$ we cannot exclude the possibility that the CP-I region harbors a compensatory function to the $\mathrm{CP}-\mathrm{II}$ region. This possibility was not tested.

CPXV utilizes several mechanisms of immune evasion including inhibition of TAP dependent antigen processing, inhibition of MHC class I peptide loading, inhibition of cell surface presentation of MHC class I molecules and expression of large set of immune modulating genes [43]. Whether modifying a few residues within a major protective epitope prevents the binding of neutralizing antibodies to A33 thus allowing CPXV to evade A33 immunity, remains to be demonstrated.

The immune protection conferred by VACV and its antigens, against VARV and other orthopoxviruses is based on cross-protection. This fact, and the development of subunit vaccines and monoclonal antibody-based therapeutic products, strongly suggest that sequence variation between the species should be carefully assessed. Mapping the basis for the protective ability of A33 at the single 
amino acid level, as conducted in this study, further highlights this aspect of cross-reactivity and sequence variation that affect protection.

\section{Materials and methods}

Viruses, cells and antibodies

Vero (ATCC-CCL-8), BHK 21 (ATCC-CCL-10) RK-13 (ATCC-CCL-37) and BS-C-1 (ATCC-CCL-26) cells were maintained as recommended by ATCC. Vaccinia Lister (Israel Ministry of Health), VACV-WR (ATCC VR-119), CPXV strain Brighton-red (ATCC VR-302) and IHD-J were propagated and tittered as described previously [28]. Sindbis virus (pTE32J) was prepared as described [25]. Briefly, capped pTE32J RNA was generated by in-vitro transcription using SP6 RNA polymerase and transfected to BHK-21 cells using Lipofectin (invitrogen) according to the manufacturer protocol. Viruses were collected from the culture medium 48 hours post transfection, reinfected to BHK-21 cells and the viruses were collected from the culture medium, concentrated by the slow addition of Polyethylene-glycol (PEG) 8,000 and $\mathrm{NaCl}$ (Sigma) to reach a 40\% PEG $2 \mathrm{~N} \mathrm{NaCl}$ concentration. Following 60 minutes incubation at $4{ }^{\circ} \mathrm{C}$, viruses were pelleted at $11,000 \mathrm{~g}$ for 60 minutes at $4^{\circ} \mathrm{C}$, and the pellet was resuspended in PBS. The concentrated viruses were titrated on BHK cells and maintained in aliquots at $-80^{\circ} \mathrm{C}$. A33 antisera was generated as described [44]. Mouse anti $\beta$ Tubulin antibody was purchased from Sigma. Mouse and rabbit anti Sindbis antisera were generated by repeated vaccination of mice and rabbits with Sindbis virus. Rabbit anti A33 was obtained by repeated vaccination with bacterially expressed, affinity purified, His-tagged A33.

\section{DNA sequences and CTL predictions}

The following sequences were used for DNA sequence alignments: VACV-WR (Vaccinia virus WR, accession\# NC006998), CPXV-BR (Cowpox virus Brighton-red, NC003663), VACV-Lister (AY678276), ECTV-Moscow (Ectromelia virus Moscow, NC004105), MPXV-ZAR (Monkeypox virus Zair, NC003310) and VARV-BGD74_ sol (Variola virus Bangladesh 1974, DQ441422). Prediction of CTL epitopes were performed using NetMHC (http://www.cbs.dtu.dk/services/NetMHC), SYFPEITHI (http://www.syfpeithi.de/bin/MHCServer.dll/EpitopePre diction.htm), and BIMAS (http://www-bimas.cit.nih. gov/molbio/hla_bind).

\section{Cloning and expression of $A 33$}

A33R gene from VACV Lister or CPXV Brighton-red DNA was amplified and cloned to the $\mathrm{pH} 3$ shuttle vector and transferred to the pTE3 vector [25]. Point mutations and domain swapping were generated by PCR, and validated by DNA sequencing. Expression of A33 in BHK-21 infected cells was determined by immunofluorescence microscopy and western blotting as previously described [45] using rabbit anti-A33 antibody, mouse anti-Sindbis antibody and anti $\beta$-Tubulin (Sigma) antibody. HRP, Alexa-fluor 488 and Alexa-fluor 555 conjugated antirabbit and anti-mouse conjugated antibodies (Molecular probes) were used according to the manufacturer's protocols. DAPI (Sigma) was used according to the manufacturer's protocols to stain nuclear DNA. Immunofluorescent microscopy was performed using an axiovert Zeiss microscope. Image acquisition was performed, maintaining the same settings for all samples, using a DS-Ril CCD (Nikon). Bacterially expressed, His-tagged A33, was used for rabbits immunization. To achieve that goal, $\mathrm{A} 33^{\mathrm{VACV}}$ from VACV Lister was cloned into pRSET plasmid (invitrogen) and expressed in BL21::pLysS bacteria. A33 was purified from the cell lysates on a Nickelagarose (NiNTA) column (Qiagen) according to the manufacturer's protocol, analyzed on SDS-PAGE and formulated for vaccination with complete or incomplete Freund adjuvant (Sigma) according to the manufacturer protocols.

\section{Enzyme linked immunosorbent assay (ELISA)}

Antibody titer to Vaccinia virus was determined by ELISA as described [28]. Briefly, microtiter plates were coated with $50 \mathrm{ng}$ purified bacterially expressed $6 \mathrm{xHis}$ tagged $\mathrm{A} 33^{\mathrm{VACV}}$. The protein was purified from whole $8 \mathrm{M}$ Urea denatured bacterial lysates on a NiNTA resin (Qiagen) and dialyzed against PBS. Following adsorption, plates were blocked, incubated with two-fold serial serum dilutions and then subsequently with alkaline phosphatase conjugated goat anti mouse IgG (1:1000, Sigma-Aldrich). GMT and GeoSTDEV were calculated as described [28].

\section{Comet inhibition assay}

Comet inhibition assay in mouse sera was determined as described previously [23]. Briefly, fresh preparation of IHD-J, diluted in Earle's modified Eagle medium, supplemented with $2 \%$ heat-inactivated fetal bovine serum to give approximately 50 plaques was used to infect monolayers of BS-C- 1 cells. After $2 \mathrm{~h}$ at $37^{\circ} \mathrm{C}$, the inoculum was removed and the cells were washed. A liquid overlay, consisting of Earle's modified Eagle medium, supplemented with $2 \%$ heat-inactivated fetal bovine serum and serial dilutions of sera obtained from the A33 vaccinated mice as indicated. After $48 \mathrm{~h}$, the medium was aspirated and the cells were stained - fixed with $0.1 \%$ (W/V) crystal-violet (Merk) in $20 \%$ ethanol. The stain was aspirated and the wells were washed with tapwater and dried. Comet inhibition capacity is determined by the minimal serum dilution exhibiting such activity. 


\section{Mice vaccination and challenge}

BALB/C and CD-1 female mice (5-7 weeks old, Charles Rivers, UK) were vaccinated by intraperitoneal injection (i.p) with $1 \times 10^{7} \mathrm{pfu}$ of the various Sindbis viruses diluted in phosphate buffered saline (PBS). Intranasal challenge with VACV-WR or CPXV was performed as previously described [28]. To induce pocks on the tails, CD-1 mice were similarly vaccinated with the various Sindbis viruses or with $1 \times 10^{6} \mathrm{pfu}$ of VACV-Lister by tail scarification and 14 days later were intravenously injected with $1 \times 10^{4}$ pfu of VACV-WR. 8 days later the tails were stained with $0.1 \%$ Trypan blue and pocks were counted. The method of tail scarification as well as the calculation of the lethal dose of $50 \%$ for $\mathrm{BALB} / \mathrm{c}$ mice $\left(\mathrm{LD}_{50}\right)$ were performed as described [28]. The end-points were weight loss of $40 \%$ of the initial weight and/or the inability to respond to the righting reflex. Animals that reached these predetermined endpoints were humanely sacrificed. $\mathrm{LD}_{50}$ values by i.n. instillation in $\mathrm{BALB} / \mathrm{c}$ mice were determined as: $2 \times 10^{4} \mathrm{pfu}$ for VACV-WR, $1 \times 10^{5}$ pfu for CPXV and 1 pfu for ECTV. $\mathrm{LD}_{50}$ of ECTV by i.f.p. injection was $10 \mathrm{pfu}$. Injection i.v. of $1 \times 10^{4} \mathrm{pfu}$ VACV-WR to CD-1 mice was not lethal. Animal experiments were repeated at least twice and conducted in compliance with the regulations for animal experiments of the IACUC at the Israel Institute for Biological Research.

\section{In-vivo cytotoxicity assay}

MHC class I-dependent cytotoxicity assay was modified from [46]. In brief, syngeneic splenocytes were harvested from naïve $\mathrm{BALB} / \mathrm{c}$ mice and labeled with either DiI or $\mathrm{DiD}$ (invitrogen) according to the manufacturer manual. Dil labeled cells were pulsed with a vaccinia CD8+ T-cell epitope with the amino acids sequence KYGRLFNEI (corresponding to - $\mathrm{A} 52^{\mathrm{VACV}}$ 75-83) [47] or with the putative $\mathrm{K}^{\mathrm{d}} \mathrm{T}$-cell epitope from $\mathrm{A} 33^{\mathrm{CPXV}}{ }_{104-112}$ (YYQGSCYIF) or with the putative $\mathrm{K}^{\mathrm{d}} \mathrm{T}$-cell epitope from $\mathrm{A} 33^{\mathrm{VACV}}{ }_{104-112}$ (YYQGSCYIL) at a final concentration of $1 \mu \mathrm{g} / \mathrm{ml}$. DiD labeled cells were pulsed with a T-cell epitope of influenzaA/H3N2/Texas/1/77 NP $147-158$ (TYQRTRALVRTG) [37] as control at a final concentration of $1 \mu \mathrm{g} / \mathrm{ml}$. A52 ${ }^{\mathrm{VACV}}{ }_{5-83}$ and influenza-A/H3N2/Texas/1/77 $\mathrm{NP}_{147-158}$ are restricted to $\mathrm{K}^{\mathrm{d}}$. DiI and DiD labeled cells were mixed to $1: 1$ ratio and $2 \times 10^{7}$ cells were injected into the tail vain of naive or vaccinated BALB/c mice. 4 hours after injection recipient animals were sacrificed and their spleens were removed. The amount of DiI and DiD labeled cells from the spleens was determined by flow cytometry (FACScalibur, BD) and analyzed with the Flowjo software (Tree Star). Specific lysis was calculated with the following formula:

$$
\% \text { specific lysis }=\left[1-\frac{\text { ratio unvaccinated }}{\text { ratio vaccinated }}\right] \times 100
$$

$$
\text { Where ratio }=\frac{\% \text { DiD labelled cells }}{\% \text { Dil labelled cells }}
$$

\section{Statistical analysis}

The area under the curve (AUC) to compare morbidity based on weight loss was calculated for each mouse and mean AUC's of various groups were compared using two-sample Student $t$-test (GraphPad Prism, Irvine, CA). Significance between antibody titers was calculated using two-tailed, unpaired Student $t$-test (GraphPad Prism, Irvine, CA).

\section{Competing interests}

The authors declare that they have no competing interests.

\section{Authors' contributions}

NP and SL and UO participated in the design of the study, carried out the experiments and drafted the manuscript. AZ performed the predictions of CTL epitopes and helped to draft the manuscript. SM, TI and NE participated in the design of the study and helped to draft the manuscript. DBN, RL, BL, $\mathrm{OI}$, DS and BP helped to carry out the experiments. All authors read and approved the manuscript.

\section{Acknowledgments}

We would like to thank C. Rice from the Rockefeler University for providing us with the PTE32J plasmids, I. glinert for language corrections and T. Waner, Y. Shlomovich, B. Sharabi and S. Abraham for assistance with animal husbandry.

\section{Author details}

'Department of Infectious Diseases, Israel Institute for Biological Research, P.O. box 19, Ness-Ziona 74100, Israel. ²Department of Biochemistry and Molecular Biology, Israel Institute for Biological Research, P.O. box 19, Ness-Ziona 74100, Israel.

Received: 16 May 2013 Accepted: 5 July 2013

Published: 10 July 2013

\section{References}

1. Fenner F, Henderson DA, Artia I, Jezek Z, Ladnyi ID: Smallpox and its Eradication. Geneva: World Health Organization; 1998.

2. Damon IK: Poxviruses, vol. 2. Philadelphia: Wolterskluwer, Lippincott, Williams \& Wilkins; 2007.

3. Fang M, Cheng H, Dai Z, Bu Z, Sigal LJ: Immunization with a single extracellular enveloped virus protein produced in bacteria provides partial protection from a lethal orthopoxvirus infection in a natural host. Virology 2006, 345(1):231-243.

4. Fogg C, Lustig S, Whitbeck JC, Eisenberg RJ, Cohen GH, Moss B: Protective immunity to vaccinia virus induced by vaccination with multiple recombinant outer membrane proteins of intracellular and extracellular virions. J Virol 2004, 78(19):10230-10237.

5. Heraud JM, Edghill-Smith Y, Ayala V, Kalisz I, Parrino J, Kalyanaraman VS, Manischewitz J, King LR, Hryniewicz A, Trindade CJ, et al: Subunit recombinant vaccine protects against monkeypox. J Immunol 2006, 177(4):2552-2564

6. Hooper JW, Custer DM, Schmaljohn CS, Schmaljohn AL: DNA vaccination with vaccinia virus L1R and A33R genes protects mice against a lethal poxvirus challenge. Virology 2000, 266(2):329-339.

7. Hooper JW, Custer DM, Thompson E: Four-gene-combination DNA vaccine protects mice against a lethal vaccinia virus challenge and elicits appropriate antibody responses in nonhuman primates. Virology 2003, 306(1):181-195.

8. Hooper JW, Ferro AM, Golden JW, Silvera P, Dudek J, Alterson K, Custer M, Rivers B, Morris J, Owens $G$, et al: Molecular smallpox vaccine delivered by alphavirus replicons elicits protective immunity in mice and non-human primates. Vaccine 2009, 28(2):494-511. 
9. Hooper JW, Golden JW, Ferro AM, King AD: Smallpox DNA vaccine delivered by novel skin electroporation device protects mice against intranasal poxvirus challenge. Vaccine 2007, 25(10):1814-1823.

10. Hooper JW, Thompson E, Wilhelmsen C, Zimmerman M, Ichou MA, Steffen SE, Schmaljohn CS, Schmaljohn AL, Jahrling PB: Smallpox DNA vaccine protects nonhuman primates against lethal monkeypox. J Virol 2004, 78(9):4433-4443.

11. Sakhatskyy P, Wang S, Chou TH, Lu S: Immunogenicity and protection efficacy of monovalent and polyvalent poxvirus vaccines that include the D8 antigen. Virology 2006, 355(2):164-174.

12. Sakhatskyy P, Wang S, Zhang C, Chou TH, Kishko M, Lu S: Immunogenicity and protection efficacy of subunit-based smallpox vaccines using variola major antigens. Virology 2008, 371(1):98-107.

13. Xiao Y, Aldaz-Carroll L, Ortiz AM, Whitbeck JC, Alexander E, Lou H, Davis HL, Braciale TJ, Eisenberg RJ, Cohen GH, et al: A protein-based smallpox vaccine protects mice from vaccinia and ectromelia virus challenges when given as a prime and single boost. Vaccine 2007, 25(7):1214-1224.

14. Payne LG: Characterization of vaccinia virus glycoproteins by monoclonal antibody precipitation. Virology 1992, 187(1):251-260.

15. Roper RL, Payne LG, Moss B: Extracellular vaccinia virus envelope glycoprotein encoded by the A33R gene. J Virol 1996, 70(6):3753-3762

16. Wolffe EJ, Weisberg AS, Moss B: The vaccinia virus A33R protein provides a chaperone function for viral membrane localization and tyrosine phosphorylation of the A36R protein. J Virol 2001, 75(1):303-310.

17. Grosenbach DW, Hansen SG, Hruby DE: Identification and analysis of vaccinia virus palmitylproteins. Virology 2000, 275(1):193-206.

18. Ward BM, Weisberg AS, Moss B: Mapping and functional analysis of interaction sites within the cytoplasmic domains of the vaccinia virus A33R and A36R envelope proteins. J Virol 2003, 77(7):4113-4126.

19. Breiman A, Carpentier DC, Ewles HA, Smith GL: Transport and stability of the vaccinia virus $A 34$ protein is affected by the $A 33$ protein. $J$ Gen Virol 2013, 94(Pt 4):720-725

20. Roper RL, Wolffe EJ, Weisberg A, Moss B: The envelope protein encoded by the $\mathrm{A} 33 \mathrm{R}$ gene is required for formation of actin-containing microvilli and efficient cell-to-cell spread of vaccinia virus. J Virol 1998, 72(5):4192-4204

21. Rottger S, Frischknecht F, Reckmann I, Smith GL, Way M: Interactions between vaccinia virus IEV membrane proteins and their roles in IEV assembly and actin tail formation. J Virol 1999, 73(4):2863-2875.

22. Smith GL, Vanderplasschen A, Law M: The formation and function of extracellular enveloped vaccinia virus. J Gen Virol 2002, 83(Pt 12):2915-2931.

23. Lustig S, Fogg C, Whitbeck JC, Eisenberg RJ, Cohen GH, Moss B: Combinations of polyclonal or monoclonal antibodies to proteins of the outer membranes of the two infectious forms of vaccinia virus protect mice against a lethal respiratory challenge. J Virol 2005, 79(21):13454-13462.

24. Chen Z, Earl P, Americo J, Damon I, Smith SK, YU F, Sebrell A, Emerson S, Cohen G, Eisenberg RJ, et al: Characterization of chimpanzee/human monoclonal antibodies to vaccinia virus A33 glycoprotein and its variola virus homolog in vitro and in a vaccinia virus mouse protection model. J Virol 2007, 81(17):8989-8995.

25. Hahn CS, Hahn YS, Braciale TJ, Rice CM: Infectious Sindbis virus transient expression vectors for studying antigen processing and presentation. Proc Natl Acad Sci USA 1992, 89(7):2679-2683.

26. Golden JW, Hooper JW: Heterogeneity in the A33 protein impacts the cross-protective efficacy of a candidate smallpox DNA vaccine. Virology 2008, 377(1):19-29.

27. He Y, Wang Y, Struble EB, Zhang P, Chowdhury S, Reed JL, Kennedy M, Scott DE, Fisher RW: Epitope mapping by random peptide phage display reveals essential residues for vaccinia extracellular enveloped virion spread. Virol J 2012, 9:217.

28. Melamed S, Paran N, Katz L, Ben-Nathan D, Israely T, Schneider P, Levin R, Lustig S: Tail scarification with Vaccinia virus Lister as a model for evaluation of smallpox vaccine potency in mice. Vaccine 2007, 25(45):7743-7753.

29. Paran N, Suezer Y, Lustig S, Israely T, Schwantes A, Melamed S, Katz L, Preuss T, Hanschmann KM, Kalinke U, et al: Postexposure immunization with modified vaccinia virus Ankara or conventional Lister vaccine provides solid protection in a murine model of human smallpox. J Infect Dis 2009, 199(1):39-48.

30. Parker S, Siddiqui AM, Oberle C, Hembrador E, Lanier R, Painter G, Robertson A, Buller RM: Mousepox in the C57BL/6 strain provides an improved model for evaluating anti-poxvirus therapies. Virology 2009, 385(1):11-21.
31. Duraffour S, Mertens B, Meyer H, van den Oord JJ, Mitera T, Matthys $P$, Snoeck R, Andrei G: Emergence of cowpox: study of the virulence of clinical strains and evaluation of antivirals. PLoS One 2013, 8(2):e55808.

32. McCollum AM, Austin C, Nawrocki J, Howland J, Pryde J, Vaid A, Holmes D, Weil MR, Li Y, Wilkins K, et al: Investigation of the first laboratory-acquired human cowpox virus infection in the United States. J Infect Dis 2012, 206(1):63-68.

33. Nielsen M, Lundegaard C, Worning P, Lauemoller SL, Lamberth K, Buus S, Brunak S, Lund O: Reliable prediction of T-cell epitopes using neural networks with novel sequence representations. Protein Sci 2003, 12(5):1007-1017.

34. Parker KC, Bednarek MA, Coligan JE: Scheme for ranking potential HLA-A2 binding peptides based on independent binding of individual peptide side-chains. J Immunol 1994, 152(1):163-175.

35. Rammensee $H$, Bachmann J, Emmerich NP, Bachor OA, Stevanovic S: SYFPEITHI: database for MHC ligands and peptide motifs. Immunogenetics 1999, 50(3-4):213-219.

36. Tscharke DC, Woo WP, Sakala IG, Sidney J, Sette A, Moss DJ, Bennink JR, Karupiah G, Yewdell JW: Poxvirus CD8+ T-cell determinants and crossreactivity in BALB/c mice. J Virol 2006, 80(13):6318-6323.

37. Levi $R$, Arnon R: Synthetic recombinant influenza vaccine induces efficient long-term immunity and cross-strain protection. Vaccine 1996, 14(1):85-92.

38. Sidney J, Assarsson E, Moore C, Ngo S, Pinilla C, Sette A, Peters B: Quantitative peptide binding motifs for 19 human and mouse MHC class I molecules derived using positional scanning combinatorial peptide libraries. Immunome Res 2008, 4:2.

39. Moutaftsi M, Peters B, Pasquetto $V$, Tscharke DC, Sidney J, Bui HH, Grey H, Sette A: A consensus epitope prediction approach identifies the breadth of murine $\mathrm{T}(\mathrm{CD} 8+)$-cell responses to vaccinia virus. Nat Biotechnol 2006, 24(7):817-819.

40. Lustig S, Fogg C, Whitbeck JC, Moss B: Synergistic neutralizing activities of antibodies to outer membrane proteins of the two infectious forms of vaccinia virus in the presence of complement. Virology 2004, 328(1):30-35.

41. Sirven P, Castelli FA, Probst A, Szely N, Maillere B: In vitro human CD4+ $T$ cell response to the vaccinia protective antigens $B 5 R$ and $A 33 R$. Mol Immunol 2009, 46(7):1481-1487.

42. Thornburg NJ, Ray CA, Collier ML, Liao HX, Pickup DJ, Johnston RE: Vaccination with Venezuelan equine encephalitis replicons encoding cowpox virus structural proteins protects mice from intranasal cowpox virus challenge. Virology 2007, 362(2):441-452

43. McCoy WH, Wang X, Yokoyama WM, Hansen TH, Fremont DH: Cowpox virus employs a two-pronged strategy to outflank $\mathrm{MHCl}$ antigen presentation. Mol Immunol 2013, 55(2):156-158.

44. Erez N, Paran N, Maik-Rachline G, Politi B, Israely $T$, Schnider P, Fuchs $P$, Melamed S, Lustig S: Induction of cell-cell fusion by ectromelia virus is not inhibited by its fusion inhibitory complex. Virol J 2009, 6:151.

45. Paran N, De Silva FS, Senkevich TG, Moss B: Cellular DNA ligase I is recruited to cytoplasmic vaccinia virus factories and masks the role of the vaccinia ligase in viral DNA replication. Cell Host Microbe 2009, 6(6):563-569.

46. Xu RH, Fang M, Klein-Szanto A, Sigal LJ: Memory CD8+ T cells are gatekeepers of the lymph node draining the site of viral infection. Proc Natl Acad Sci USA 2007, 104(26):10992-10997.

47. Oseroff C, Peters B, Pasquetto V, Moutaftsi M, Sidney J, Panchanathan V, Tscharke DC, Maillere B, Grey H, Sette A: Dissociation between epitope hierarchy and immunoprevalence in CD8 responses to vaccinia virus western reserve. J Immunol 2008, 180(11):7193-7202.

doi:10.1186/1743-422X-10-229

Cite this article as: Paran et al:: Active vaccination with vaccinia virus A33 protects mice against lethal vaccinia and ectromelia viruses but not against cowpoxvirus; elucidation of the specific adaptive immune response. Virology Journal 2013 10:229. 